\title{
Evaluating fatigue crack propagation properties using a cylindrical rod specimen
}

\author{
C.S. Shin *, C.Q. Cai \\ Department of Mechanical Engineering, National Taiwan University, No. 1, Sec. 4, Roosevelt Road, Taipei 10617, Taiwan, Republic of China
}

Received 29 September 2005; received in revised form 23 May 2006; accepted 11 June 2006

Available online 14 August 2006

\begin{abstract}
In the evaluation of fatigue crack propagation properties, standard specimens such as the compact tension (CT) or center cracked specimens are commonly employed. However, these specimens are not applicable when the available material for testing is of a long axial length but small cross-sectional area. Surface cracked rod specimens may be used for this purpose. In the current work, to shed light on their applicability to the evaluation of fatigue crack propagation properties, surface cracked rod specimens were tested under axial tension. The development of the surface cracks was examined. Fatigue crack propagation data at the surface and in the deepest interior point of the surface cracks in different diameter rods were obtained. Comparison showed that rods with diameters of 8 mm and larger give fatigue crack propagation data similar to that given by compact tension specimens. For a 6 mm diameter rod specimen, growth rates were slightly higher than the standard if correlated in terms of $\Delta K$ but, fall in line with the standard, if crack closure was taken into account.
\end{abstract}

(C) 2006 Elsevier Ltd. All rights reserved.

Keywords: Surface crack shape development; Fatigue crack propagation; Surface crack measurement; Rod specimen

\section{Introduction}

Knowledge of the mechanical properties, particularly fatigue crack propagation properties, of mechanical components is one of the starting points for reliable integrity assessment and residual life prediction of structures. In the evaluation of fatigue crack propagation properties, standard specimens such as the compact tension (CT) or center cracked specimens are commonly employed. However, these specimens are not applicable when the available material for testing is of a long axial length but small crosssectional area. This is the case for cylindrical shaped components such as pins, bolts and reinforcement wires. Boat samples taken from a large structure for evaluating the aging degradation of mechanical properties are often of large aspect ratio and small cross-section. A further example of this category is the specimens for testing irradiation

\footnotetext{
${ }^{*}$ Corresponding author. Tel./fax: +886223622160.

E-mail address: csshin@ntu.edu.tw (C.S. Shin).
}

degradation or for surveillance purpose inside the nuclear reactor vessel [1]. These specimens are limited in size and number and it would be helpful if fatigue crack propagation tests could be based on remnants of specimens used for other testing. At present, a large amount of work have been made on the technique of using small amounts of materials for the evaluation of impact and fracture toughness properties [1-3]. Similar studies on fatigue properties testing are relatively limited [4-11] and most of them are confined to evaluation of stress/strain-life curves. A recent work compared a number of three-point bending specimens [12]. Although results from all the bend specimens were deemed acceptable, those from the standard Charpy specimen had a slightly but consistently lower growth rates than the other specimens at stress intensity range greater than $20 \mathrm{MPa} \sqrt{ } \mathrm{m}$. Hence the results may not be on the conservative side. A modified Charpy specimen has better agreement with the standard CT or three-point-bend specimens. However, the modified Charpy specimen has a width double that of a standard Charpy specimen and is 


\section{Nomenclature}

a depth of a surface crack in $\mathrm{mm}$

$b \quad$ semi-major axis of an elliptical crack in $\mathrm{mm}$

$A_{\mathrm{c}} \quad$ area of the surface crack

$D \quad$ rod diameter in $\mathrm{mm}$

$\frac{\mathrm{d} a}{\mathrm{~d} N} \quad$ fatigue crack growth rate

$\stackrel{\mathrm{d} N}{E} \quad$ Young's modulus in $\mathrm{GPa}$

$F_{i} \quad$ geometry correction factor in stress intensity expression $K_{i}$

$K_{i} \quad$ stress intensity factor at point $i$
$\Delta K_{i} \quad$ stress intensity range at point $i$

$\Delta K \quad$ stress intensity range

$\Delta K_{\text {eff }} \quad$ effective stress intensity range

NA Normalized area $=\frac{4 A_{\mathrm{c}}}{\pi D^{2}}$

$2 S$ surface arc length of a crack in $\mathrm{mm}$

$X \quad$ Normalized compliance $=\frac{E}{1000} \frac{\varepsilon_{\mathrm{B}}}{\sigma}$

$\sigma \quad$ nominal axial stress

$\varepsilon_{\mathrm{B}} \quad$ back-face strain more demanding on the size of the sample. A surface cracked rod specimen [13] is also suited for the above purpose. However, the rod specimens in Ref. [13] were tested under rotating bending. While that is highly cost-effective, the flexibility to vary the load ratio and convenience in monitoring the crack dimensions and premature crack closure are sacrificed. In the current work, surface cracked rod specimens are tested under axial tension. Fatigue crack propagation data at the surface and in the deepest interior point of the surface cracks in different rod diameters were obtained. These were compared with the results obtained from standard CT specimens to shed more light on the applicability and limitation of using the rod specimens to evaluate fatigue crack propagation properties.

\section{Experimental procedures}

AISI 304 stainless steel was employed as the testing material. Standard compact tension (CT) specimens (50 $\mathrm{mm}$ wide $\times 18 \mathrm{~mm}$ thick) conforming to ASTM E647 as well as rod specimens $(15 \mathrm{~mm}$ in diameter and $200 \mathrm{~mm}$ long) were machined from a plate stock. Fatigue crack propagation data from these CT specimens served as a reference to assess whether the rod specimen results accurately reflect the standard fatigue crack propagation data. Further evaluation of the size effect was carried out in rods with the same length but having diameters of $15,10,8$ and $6 \mathrm{~mm}$. To avoid excessive machining and waste of material, this latter batch of rod specimens were fabricated from a $15 \mathrm{~mm}$ diameter ground rod stock. The composi- tions and tensile properties of the two stocks are listed in Table 1. Although both comply with the standard material specifications, the plate stock and rod stock materials have slightly different compositions. Moreover, the two stocks obviously have undergone different fabrication routes. These lead to slight differences in strengths and somewhat more difference in the percentage elongation. Such differences however will not affect our later results as cross-comparison between the two stocks have not been made.

At the center of each rod specimen, a roughly semi-elliptical surface starter notch was created by electric-discharge machining using a thin circular copper foil electrode. The diameters of the electrode were chosen to be equal to the rod diameter $(D)$. The depth of the starter notches were about $0.13 D$. This gave an aspect ratio $(a / b$, please refer to Fig. 1 for nomenclature) of about 0.5. For a limited number of specimens, an electrode diameter smaller than $D$ was employed to give a larger initial aspect ratio. Before testing, all specimens were stress relieved by a solution annealing treatment in vacuum at $1050{ }^{\circ} \mathrm{C}$ for $1 \mathrm{~h}$ followed by quick cooling in a continuous supply of argon stream.

Cyclic testing was carried out using a servo-hydraulic machine at a frequency of $15 \mathrm{~Hz}$. Constant amplitude sinusoidal waveform was used. A load ratio (min. load/max. load) of 0.1 was used for the CT specimens and 0 for the rod specimens. Surface crack length on the CT specimen was monitored with a traveling microscope to a resolution of $0.01 \mathrm{~mm}$.

The rod specimens were tested with a pair of rigid hydraulic grips. Surface crack length was monitored with

Table 1

Chemical compositions and mechanical properties of the test materials

\begin{tabular}{|c|c|c|c|c|c|c|c|c|}
\hline & \multicolumn{8}{|l|}{ Element } \\
\hline & $\mathrm{Fe}$ & $\mathrm{C}$ & $\mathrm{Si}$ & $\mathrm{Mn}$ & $\mathrm{P}$ & $\mathrm{S}$ & $\mathrm{Ni}$ & $\mathrm{Cr}$ \\
\hline \multicolumn{9}{|c|}{ Plate stock AISI 304 stainless steel } \\
\hline $\mathrm{Wt}(\%)$ & Balance & 0.06 & 0.33 & 1.26 & 0.035 & 0.02 & 8.11 & 20.36 \\
\hline \multicolumn{2}{|c|}{$0.2 \%$ Proof stress $(\mathrm{MPa})$} & \multicolumn{2}{|c|}{ Tensile strength (MPa) } & \multicolumn{3}{|c|}{ Elongation $(\%)$} & \multicolumn{2}{|c|}{ Young's modulus (GPa) } \\
\hline \multicolumn{2}{|c|}{265} & \multicolumn{2}{|c|}{646} & \multicolumn{2}{|c|}{62} & & \multicolumn{2}{|c|}{198} \\
\hline \multicolumn{9}{|c|}{ Rod stock AISI 304 stainless steel } \\
\hline $\mathrm{Wt}(\%)$ & Balance & 0.04 & 0.50 & 1.29 & 0.033 & 0.00 & 8.25 & 20.94 \\
\hline \multicolumn{2}{|c|}{$0.2 \%$ Proof stress $(\mathrm{MPa})$} & \multicolumn{2}{|c|}{ Tensile strength (MPa) } & \multicolumn{2}{|c|}{ Elongation $(\%)$} & \multicolumn{3}{|c|}{ Young's modulus (GPa) } \\
\hline 259 & & 645 & & 72.9 & & 200 & & \\
\hline
\end{tabular}




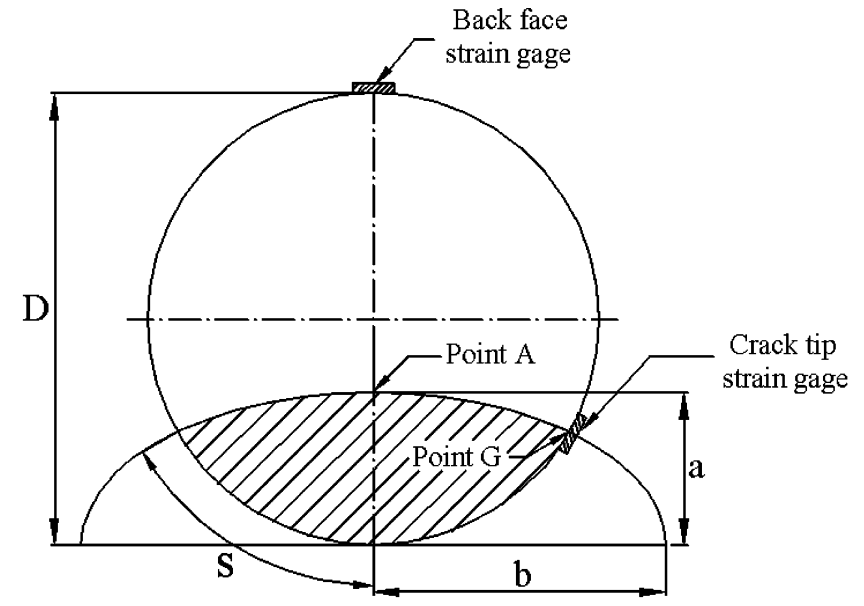

Fig. 1. Nomenclature of the surface cracked rod.

a rotary traveling microscope to a resolution of $0.026 \mathrm{~mm}$ on a $15 \mathrm{~mm}$ diameter specimen. On a few specimens, instantaneous crack fronts were recorded periodically by creating beach marks using a waveform that has the same maximum load but with the amplitude reduced to $30 \%$ of the instantaneous baseline loading. A surface crack length-compliance method [14] has also been employed on the rod specimens to monitor the crack shape development. This allowed the crack size to be measured at much closer intervals and with much less effort than the beach marking technique. More details about this method will be given in the next section. Crack growth rates are obtained from the resulting crack length-number of cycle data via a seven-point quadratic fit method and are correlated in terms of the corresponding stress intensity solution reported in Ref. [15].

Pre-matured crack closure invariably occurs during fatigue crack propagation. This is monitored with the widely used compliance technique aided with an offset method $[16,17]$.

\section{Crack shape monitoring by a normalized area-compliance method}

Owing to the non-uniform nature of the surface crack through the thickness, accurate measurement of the crack front profile is often difficult and indirect. A number of methods have been employed to measure the surface crack profile [18-22]. However, some of these involved expensive equipment and cannot provide real time on-line measurement $[18,19]$. Potential drop techniques are convenient but are susceptible to electromagnetic and other interferences [23]. Periodic beach marking [24] is straight forward and no additional equipment is required. However, it is cumbersome to carry out and cannot give measurement at close intervals. A simple method involving conventional low cost compliance monitoring plus optical measurement has been shown to give a crack depth resolution of $0.03 \mathrm{~mm}$ and an accuracy of $0.08 \mathrm{~mm}$ in practical cases
[14]. This method is employed in the current work to deduce the crack geometry.

Experimental results suggested that the surface cracks in cylindrical rods can be adequately described by a semi-elliptical profile $[13,14,25]$. To uniquely define the crack front, we need information about the crack shape (such as the aspect ratio $\frac{a}{b}$ ) and a crack dimension (such as surface crack length $2 S$ or crack depth $a$ ). Optical measurement can only give the surface crack length. Compliance is an easily measured quantity and it reflects the size of the crack relative to the net-section area. However, the relative crack size and hence the compliance are again a function of crack shape and crack depth. It has been shown numerically that a normalized compliance may be uniquely related to a single parameter, the normalized area, under different combination of crack aspect ratios and crack depths. The normalized compliance $(X)$ and normalized area (NA) are respectively defined as:

$$
\begin{aligned}
& X=\frac{E}{1000} \frac{\varepsilon_{\mathrm{B}}}{\sigma} \\
& \mathrm{NA}=4 A_{\mathrm{c}} / \pi D^{2}
\end{aligned}
$$

where $\sigma$ is the nominal axial stress in the rod in $\mathrm{MPa}, E$ is the Young's Modulus in GPa, $\varepsilon_{\mathrm{B}}$ is the back-face strain, $A_{\mathrm{c}}$ is the area of the surface crack (hatched area in Fig. 1) and $D$ is the rod diameter.

The relationship between the normalized compliance and the normalized area has been evaluated by finite element analysis. Experimental verification has also been carried out on surface cracked rod specimens with different diameters.

\section{Results and discussion}

\subsection{The normalized area-normalized compliance relationship}

The normalized areas of a number of surface cracks with crack aspect ratio $a / b$ varied from about 0.3 to 0.9 were deduced from the beach markings on some of the rod specimens. Fig. 2 shows a typical beach marked fracture surface. The instantaneous crack fronts conformed well to a semi-elliptical curve. These normalized areas and their corresponding normalized compliance deduced from back face strains for $15 \mathrm{~mm}$ diameter rods are plotted in Fig. 3. Besides experimental measurements, compliances were also computed for a number of semielliptical cracks with crack aspect ratio $a / b=0,0.6$ and 1.0 using the finite element method (FEM). These numerical results are also presented alongside with the experimental data in Fig. 3. It can be seen that all data points basically fall on a single curve. For NA $>0.7$, experimental compliance tends to be slightly higher than the numerical results. This discrepancy is more marked for NA $>0.9$. This phenomenon is presumably due to the effect of plastic zone which has not been taken into 


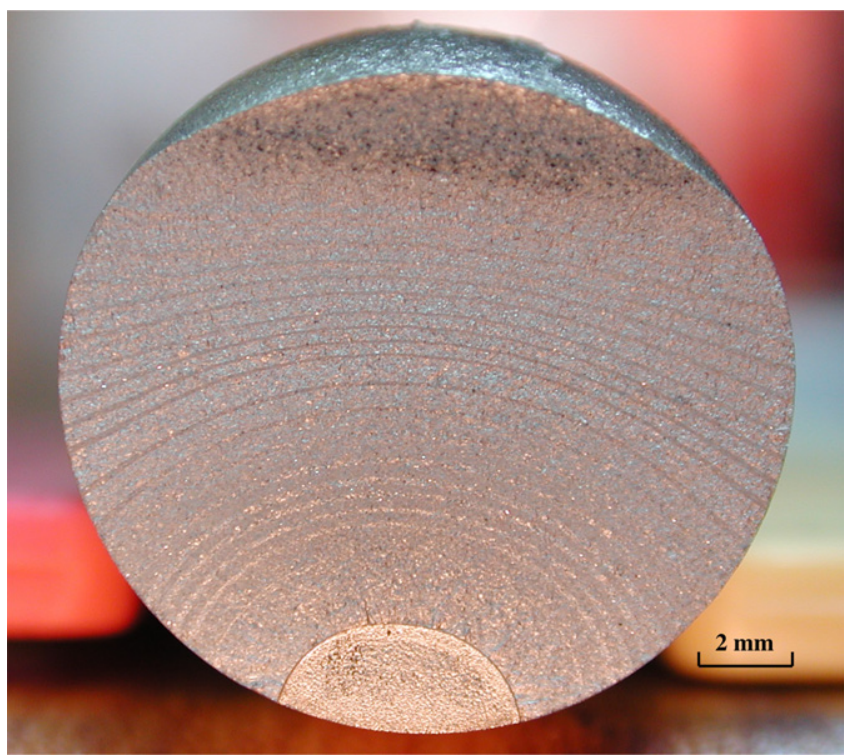

Fig. 2. A typical beach marked rod specimen fracture surface.

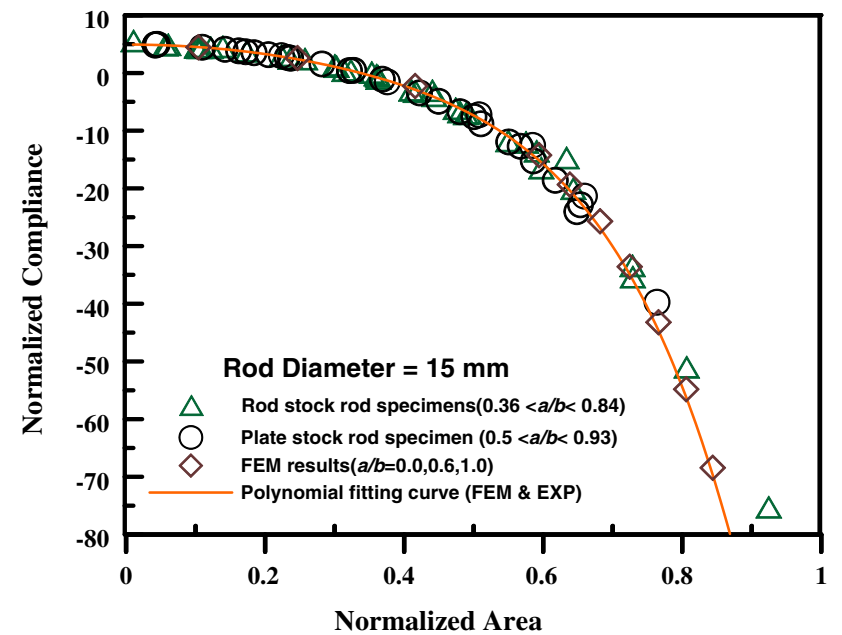

Fig. 3. Normalized compliance versus normalized area relationship for $15 \mathrm{~mm}$ diameter rod specimen.

account in the elastic finite element analysis. Fortunately, crack growth experiments stopped at NA $<0.6$ and will not be affected. Eq. (3) below describes the normalized compliance-normalized area relationship. It was obtained by curve fitting to the FEM data. The degree of the fitting polynomial was so chosen to give an error within $0.5 \%$ of the numerical results.

(i) $-2.0<X \leqslant 0.95$ or $0.04 \leqslant \mathrm{NA}<0.54$ :

$$
\begin{aligned}
\mathrm{NA}= & 0.34167-0.174981 X-0.10034 X^{2}+2.62825 \\
& \times 10^{-2} X^{3}+0.15304 X^{4}+1.87761 \times 10^{-2} X^{5} \\
& -0.149421 X^{6}-0.10801 X^{7}-2.21154 \times 10^{-2} X^{8}
\end{aligned}
$$

$$
\begin{aligned}
\text { (ii) }- & -15.0<X \leqslant-2.0 \text { or } 0.54 \leqslant \mathrm{NA}<0.87: \\
\mathrm{NA}= & 0.38076-9.48426 \times 10^{-2} X-9.70327 \times 10^{-3} X^{2} \\
& -5.34726 \times 10^{-4} X^{3}-1.10686 \times 10^{-5} X^{4}
\end{aligned}
$$

Elastic finite element analysis showed that the normalized compliance-normalized area relationship is independent of rod diameter for diameters ranging from $5 \mathrm{~mm}$ to $15 \mathrm{~mm}$ [14]. Experimental measurement show that this is the case for the $10 \mathrm{~mm}$ and $8 \mathrm{~mm}$ diameter rods as their data fall on to the best fit curve expressed by Eq. (3) (see Fig. 4). However, for the $6 \mathrm{~mm}$ diameter rods, experimental compliances are in line with the larger diameter rods only when the NA $<0.35$. For higher NA, the $6 \mathrm{~mm}$ diameter rod has significantly higher compliance. Again, this may be attributed to the effect of plastic zone which occupies a larger portion of the uncracked ligament in smaller diameter rods under the same NA. For the case of $6 \mathrm{~mm}$ diameter rod, the best fit curve to the experimental data may be expressed as:

$$
\begin{aligned}
-3 & <X \leqslant 0.95 \text { or } 0.04 \leqslant \mathrm{NA}<0.65: \\
\mathrm{NA}= & 0.37168-0.206396 X-6.84676 \times 10^{-2} X^{2} \\
& +3.04752 \times 10^{-2} X^{3}+1.52974 \times 10^{-2} X^{4} \\
& -6.02312 \times 10^{-2} X^{5}-5.85953 \times 10^{-2} X^{6} \\
& -1.94938 \times 10^{-2} X^{7}-2.23873 \times 10^{-3} X^{8}
\end{aligned}
$$

\subsection{Development of crack closure}

It is well known that the interior of a through-thickness fatigue crack will stay open for a larger portion of the loading cycle than that at the surface owing to a difference in the stress state [17]. The same phenomenon was also observed in surface cracks [26-29]. A typical back face compliance trace showed three different regimes (see

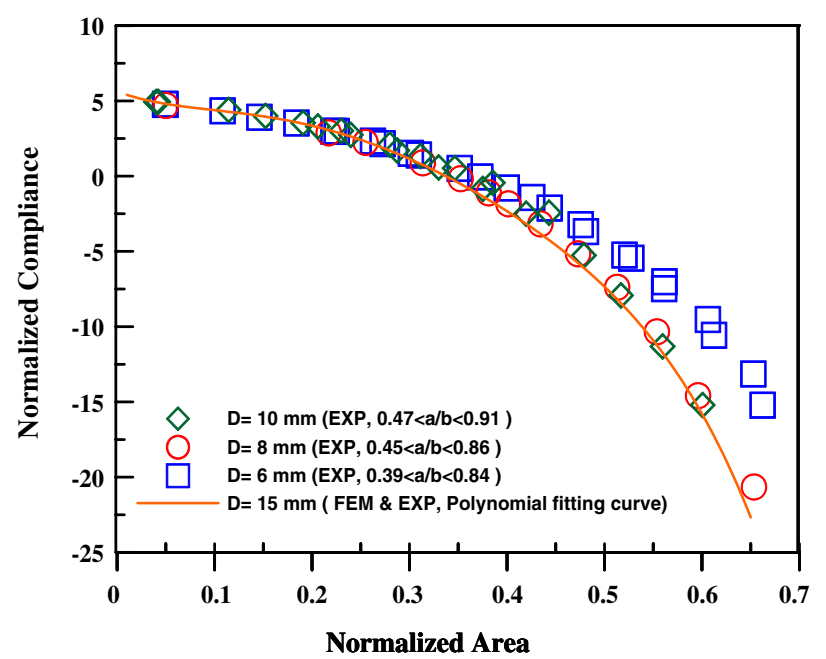

Fig. 4. Comparison of normalized compliance versus normalized area relationships for different rod specimen diameters. 
Fig. 5). On applying the offset procedure [16,17], two distinct turning points become well defined. These may be attributed to the closure of crack at the surface point $\mathrm{G}$ (upper turning point) and the deepest interior point A (lower turning point) respectively. The plane stress condition prevailing near the specimen surface will lead to a heavier plastic deformation and an earlier closure at the surface point $G$ than that at the interior point A. Compliance trace measured by a strain gage straddling the crack at the tip region indicated a closure level corresponding to the upper turning point. On unloading, the slope of the back face compliance trace starts to change as closure at the surface begins to occur, and is continuously changing as closure spreads from the surface to the interior. The point on the compliance trace that corresponds to a fully closed crack is taken to determine the crack closure load for the deepest interior point [27].

Fig. 6 shows a typical development of closure responses in terms of $\Delta K_{\mathrm{efff}} / \Delta K$ for the surface and the deepest interior points as deduced by the methods discussed above. $\Delta K$ is the applied stress intensity factor range. $\Delta K_{\text {eff }}$ is the effective stress intensity range, or the portion of applied stress intensity range during which the crack stays open. Closure is heavier on the surface than in the interior. As the crack grew, the degree of closure decreased. The surface crack became fully open everywhere during the whole loading cycle when the crack depth ratio reached 0.39 .

\subsection{Comparison of fatigue crack propagation data between $C T$ and rod specimens}

The fatigue crack propagation rate $\left(\frac{\mathrm{d} a}{\mathrm{~d} N}\right)$ versus the stress intensity range $(\Delta K)$ data derived from three $\mathrm{CT}$ specimens can be described by:

$\frac{\mathrm{d} a}{\mathrm{~d} N}=1.98 \times 10^{-9}(\Delta K)^{3.4}$

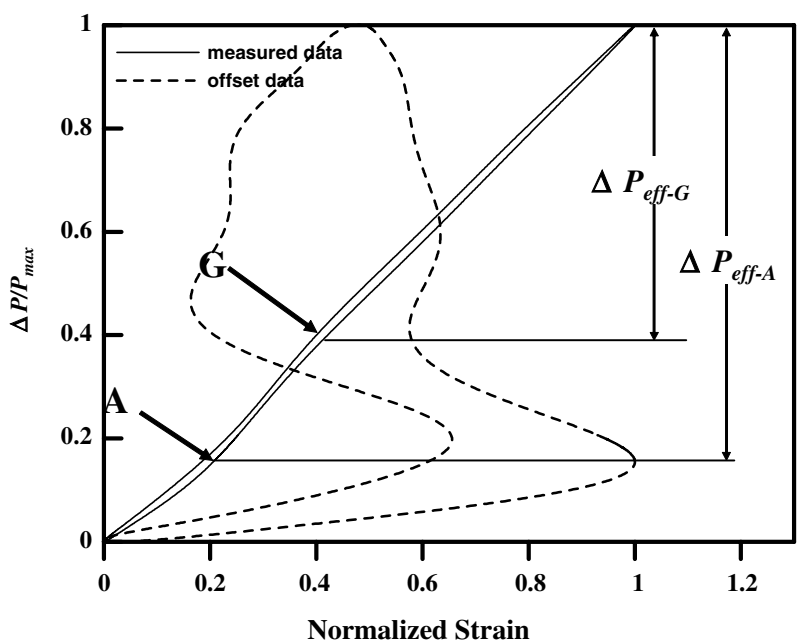

Fig. 5. Typical back-face compliance trace for identification of crack closure.

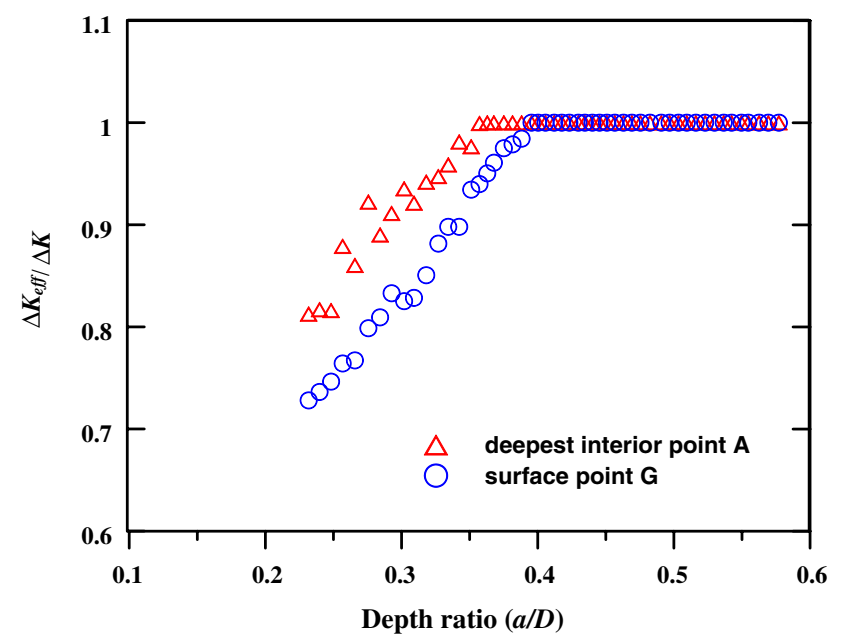

Fig. 6. Typical development of the crack closure responses at the surface and in the interior of a surface cracked rod specimen.

where $\frac{\mathrm{d} a}{\mathrm{~d} N}$ is the crack growth rate in $\mathrm{mm} /$ cycle and $\Delta K$ is in $\mathrm{MPa} \sqrt{ } \mathrm{m}$.

Tests have been repeated on four rod specimens with different initial crack shapes from the same plate stock as the CT specimens. Reproducibility of the results is quite good. Fig. 7 compares the baseline CT results with the typical crack growth responses at the deepest interior point A (diamond symbols) and the surface point $G$ (circle symbols) of a typical rod specimen. Crack growth rate at the surface point $G$ is derived from surface crack length measurement. Growth rate at the deepest interior point A is derived from the crack depth inferred from the compliance method mentioned above. $\Delta K$ values are computed using the closed form stress intensity solution reported in [14]. Broken lines in Fig. 7 are the upper and lower bounds of the CT specimen data. Agreement between the rod data with the CT results is acceptable. At low $\Delta K$ values, crack growth in the interior is slightly but consistently faster than that at

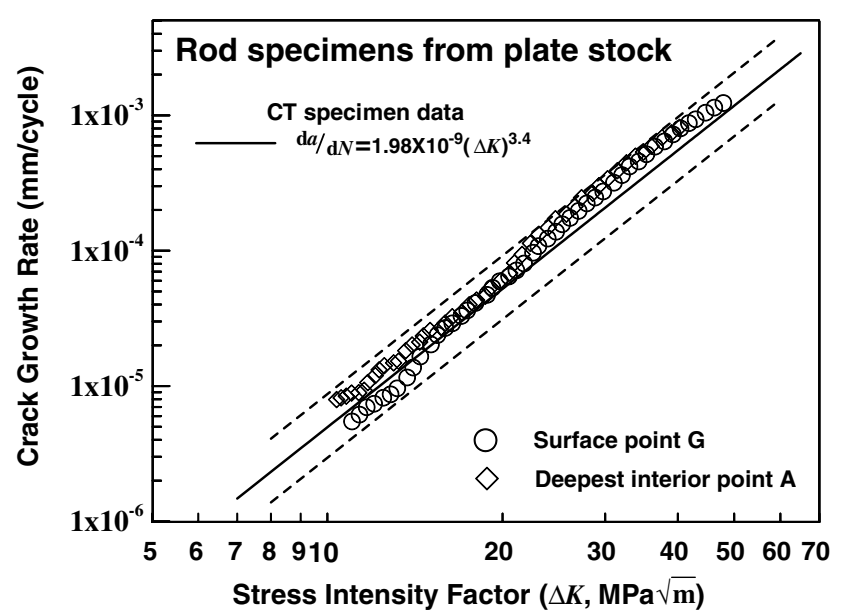

Fig. 7. Comparison of crack growth data in terms of $\Delta K$ from a typical rod specimen with baseline $\mathrm{CT}$ specimen results from the same plate stock. 
the surface. At higher $\Delta K s$ crack growth responses at the two locations merge together. This phenomenon is in line with the differences in crack closures as described above.

Fig. 8 compares the growth rate from the CT specimens with that from the four rod specimens correlated in terms of the effective stress intensity range $\Delta K_{\text {eff }}$. The baseline crack growth data from standard fatigue crack propagation testing on CT specimens may be expressed as:

$\frac{\mathrm{d} a}{\mathrm{~d} N}=9.569 \times 10^{-9}\left(\Delta K_{\text {eff }}\right)^{2.987}$

where $\frac{\mathrm{d} a}{\mathrm{~d} N}$ is the crack growth rate in $\mathrm{mm} /$ cycle and $\Delta K_{\mathrm{eff}}$ is in $\mathrm{MPa} \sqrt{ } \mathrm{m}$.

Also shown in Fig. 8 are the upper and lower bounds of the CT specimen data (broken lines). Both the surface growth and interior growth fall in line with each other and with the CT specimen scatter band throughout the whole range of $\Delta K_{\text {eff }}$ tested. This suggests that the $15 \mathrm{~mm}$ diameter surface cracked rod specimen is a useful alternative to CT specimen for obtaining the fatigue crack propagation properties.

\subsection{Development of crack shape}

From Eq. (5), the crack growth increment in one cycle is proportional to the instantaneous stress intensity range raised to the power of the Paris law exponent. Assuming that, in a small number of cycles $\Delta N$, the crack growth increment at the deepest interior point $\mathrm{A}$ is $\Delta a_{\mathrm{A}}$, the growth increment at any point $i$ on the crack front, $\Delta a_{\mathrm{A}}$, is related to $\Delta a_{\mathrm{A}}$ by:

$\Delta a_{i}=\Delta a_{\mathrm{A}}\left(\frac{\Delta K_{i}}{\Delta K_{\mathrm{A}}}\right)^{3.4}=\Delta a_{\mathrm{A}}\left(\frac{F_{i}}{F_{\mathrm{A}}}\right)^{3.4}$

where $\Delta K_{x}$ and $F_{x}$ are the instantaneous stress intensity range and the corresponding geometry correction factor at point $x$.

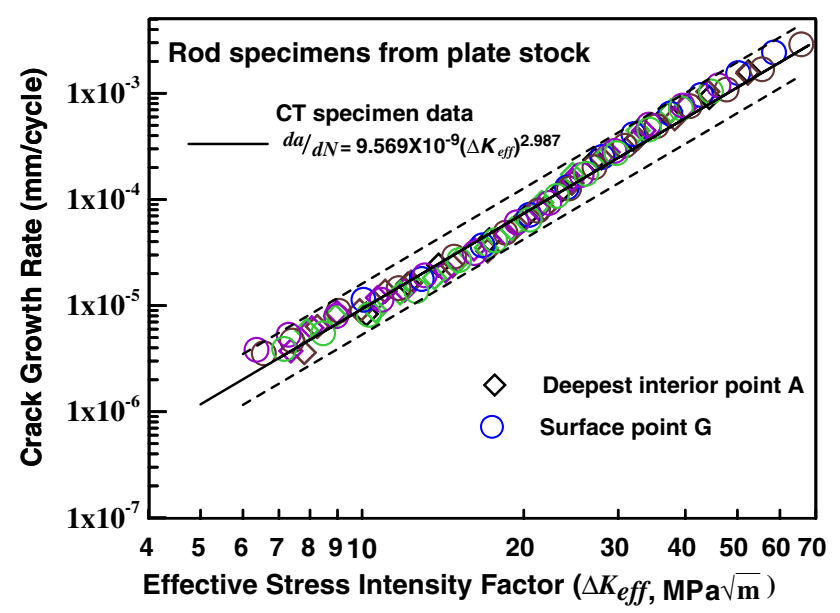

Fig. 8. Comparison of crack growth data in terms of $\Delta K_{\text {eff }}$ from four rod specimens with that from CT specimens from the same plate stock.
The geometry correction factor $F_{x}$ is a function of the crack depth ratio $a / D$, the crack aspect ratio $a / b$ and the position of the point $x$ on the crack front. For each specific crack geometry, $F_{x}$ has a characteristic pattern of variation along the crack front. Eq. (7) therefore suggests that the development of crack shape is dependent on the initial crack shape and the Paris law exponent but is independent of the applied loading. With the availability of a closed form stress intensity factor (or more precisely, geometry correction factor) solution for the whole surface crack front [14], it is quite straight forward to compute the progressive crack fronts given an initial crack shape and dimension using Eq. (5). In the current experimental work, this has been carried on using the initial crack dimensions. In practice the incremental growth chosen must be small enough to ensure there is no significant change in the local stress intensity during that increment. Trial and error showed that a $\Delta a$ smaller than $D / 400$ will give convergent results. For each successive crack front computed, a best fitted elliptical curve is evaluated and the aspect ratio $a / b$ is obtained based on the fitted curve. Solid lines in Fig. 9 show the predicted development in the crack aspect ratio $a / b$ for a series of initial crack shapes under a Paris law exponent of 3. Except for an initial circular front $(a / b=1)$, all other cracks show an initial increase and subsequent decrease in aspect ratio as they increase in depth. During the decreasing phase, different curves tend to merge together. This implies that, regardless of the initial shape, surface cracks will eventually develop into the same shape. Similar behavior is expected for other Paris law exponents. Also shown in Fig. 9 are two broken lines that represent Paris law exponent of 2 and 4 for an initial $a / b=0$. By comparing the three curves for an initial $a / b=0$, it can be seen that the effect of Paris law exponent on the aspect ratio develop is small at first but increases as the crack grows. After passing through the maximum aspect ratio, the aspect ratios under different exponents decrease at

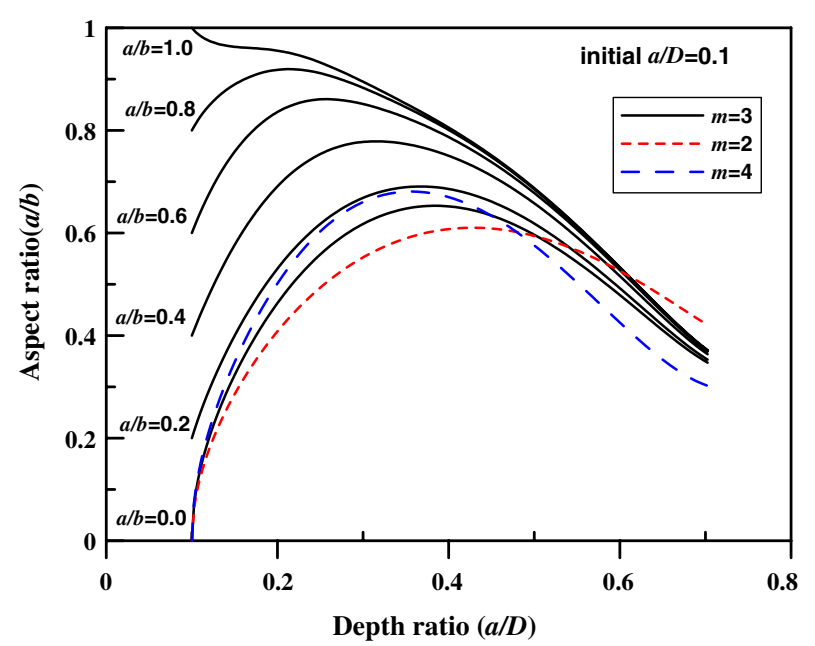

Fig. 9. Predicted development in the crack aspect ratio for a series of initial crack shapes. 
different rate and crack shapes may approach each other again. On going through the cross-over point, crack shapes diverge increasingly.

Fig. 10a and $\mathrm{b}$ compare the numerical prediction and experimentally measured crack aspect ratio development. The initial crack shape points (in black) shown for the experimental specimens are the starter notch by electric discharge machining. The overall agreement between the prediction and the measurement is reasonable. It should be noted that during pre-cracking, the crack may not initiate uniformly along the whole notch front at the same time. Besides, there is the differential crack closure effect that will affect the actual distribution along the crack front. On the other hand, the elastic solution for stress intensity solution has been employed for numerical prediction. This may explain some of the discrepancy between the measured and predicted data.

\subsection{Effect of rod diameter}

Rod specimens with diameters $10 \mathrm{~mm}, 8 \mathrm{~mm}$ and $6 \mathrm{~mm}$ had also been tested. Fig. 11 shows the measured fatigue
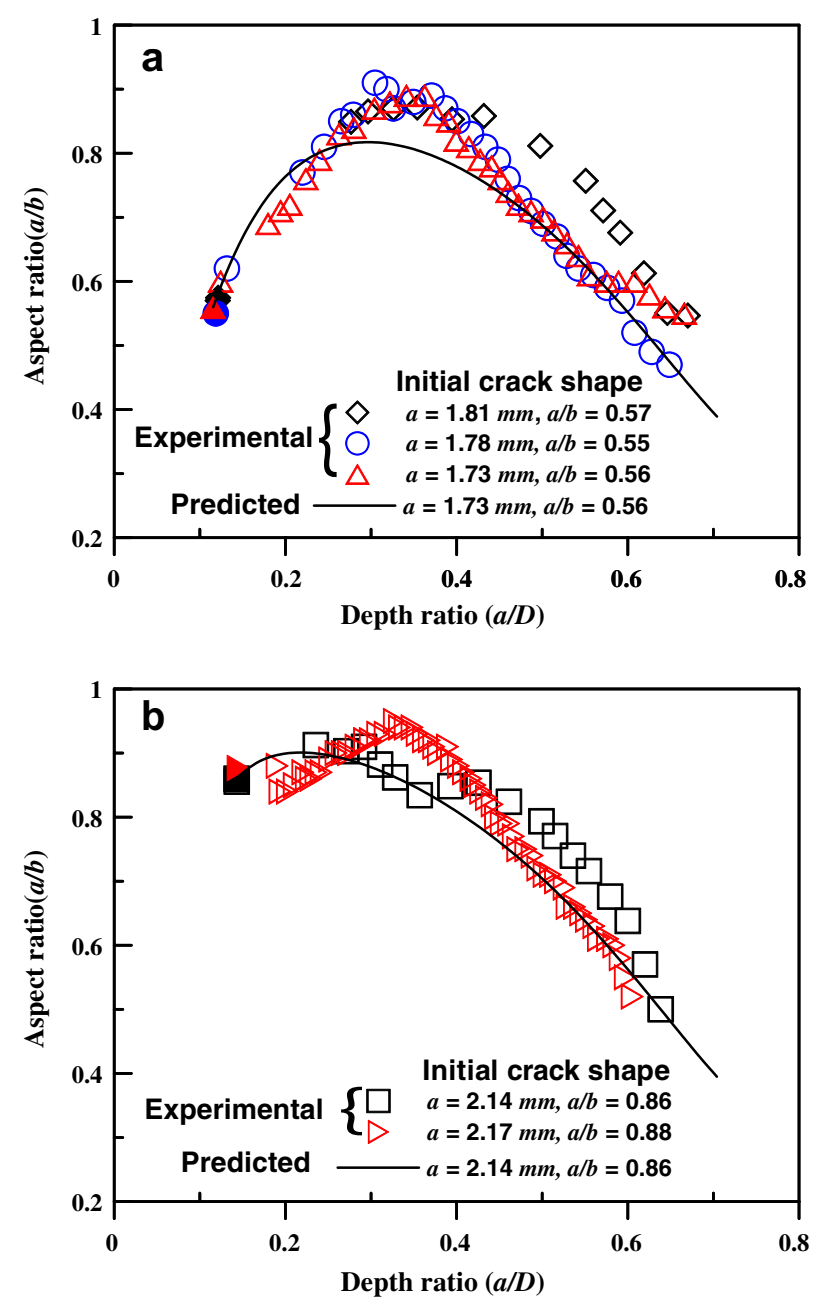

Fig. 10. Comparison between experimental and predicted crack shape development for two different initial crack shapes. crack propagation rates for different diameter rods against the applied stress intensity range. The solid line represents the Paris law fit to the crack growth data of five $15 \mathrm{~mm}$ diameter rods while the broken lines are the upper and lower bounds of the scatter of these data. The majority of growth data from smaller rods fall inside this scatter band. However, the data do not exactly center about the best fit solid line of the $15 \mathrm{~mm}$ diameter rod data. In fact, the interior growth rates of the $6 \mathrm{~mm}$ diameter rods tend to lie on and sometimes beyond the upper bound of this scatter band. This discrepancy may be related to a violation in size requirement. It may also be caused by a difference in the premature crack closure behaviors since the degrees of plasticity among the different sized rods are different. In the ASTM E647 standards for fatigue crack propagation properties evaluation [30], a size requirement is imposed to ensure that the remaining ligament is not under net section yielding and is greater than the crack tip plastic zone. In the current work, in all the rods, the net section stresses at the end of testing are slightly below the initial yield. If based on the initial yield strength, the plane stress plastic zone sizes at the end of the testing are larger than the corresponding remaining ligaments. However, the test material strain hardens heavily. If the average between the initial yield and the ultimate tensile strength is used, then all the plastic zone sizes are within the remaining ligaments. All in all, the deviations in the crack growth data among different sized rods shown in Fig. 11 are still within acceptable experimental scatter. However, since the size requirement as well as the degree of plasticity is material strength dependent, the smallest rod size applicable in the current work may or may not be applicable in a different material. It is suggested that careful validation is needed for any specific material concerned.

Fig. 12 shows the crack growth rates for different rod specimens correlated in terms of the effective stress intensity range. Again, the solid line represents the best power law fit to the $15 \mathrm{~mm}$ diameter rod results and the broken

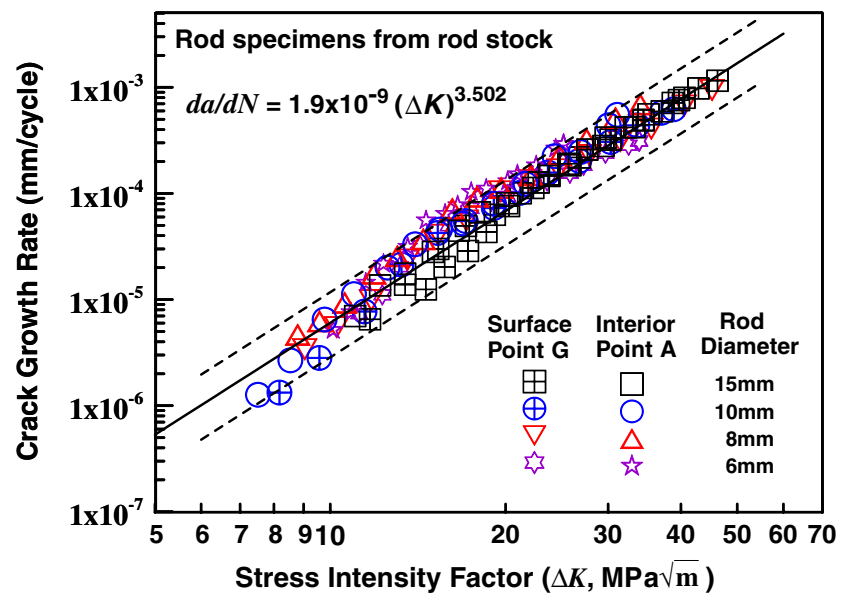

Fig. 11. Comparison of crack growth data from different sized rods in term of the stress intensity range $\Delta K$. 


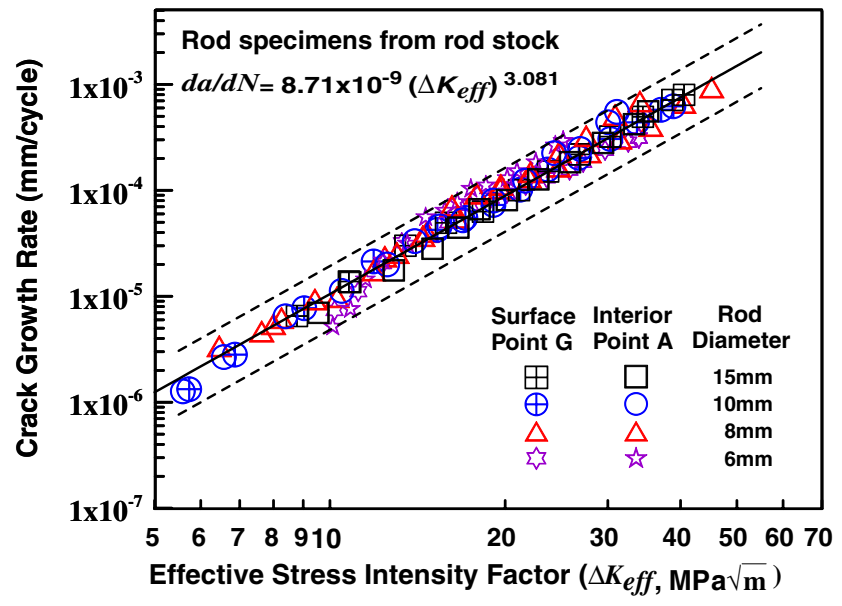

Fig. 12. Comparison of crack growth data from different sized rods in term of the effective stress intensity range $\Delta K_{\text {eff. }}$

lines bound the scatter band. By taking into account of crack closure, the growth rate data of smaller rods all fall within the scatter band of the $15 \mathrm{~mm}$ diameter rods. Moreover, the best fit straight line for the $15 \mathrm{~mm}$ diameter data is now also the best fit to the whole set of data from all the rods. This suggests that the current rod specimen is a feasible alternative to provide valid fatigue crack propagation behavior in AISI 304 stainless steel.

\section{Conclusions}

Fatigue crack propagation properties have been evaluated with a surface cracked rod specimen under axial tension in AISI 304 stainless steel. Here are the major conclusions from the study:

1. The normalized compliance-normalized area relationship for surface crack profile evaluation is size independent and agrees with elastic finite element analysis when the rod diameter is equal to or greater than $8 \mathrm{~mm}$. For $6 \mathrm{~mm}$ diameter rod, the corresponding compliance is higher than the elastic solution when the normalized area is greater than 0.35 .

2. The evolution of surface crack profile can be reasonably predicted by employing a closed form stress intensity solution for the whole crack front and the corresponding material Paris law exponent. Evolution of the crack profile is dependent on the initial crack shape and the Paris law exponent but is independent of the applied loading. Moreover, in the same material, different initial crack shapes will eventually develop into a common final shape.

3. The current rod specimen with a diameter of $8 \mathrm{~mm}$ or above is a feasible alternative to provide valid fatigue crack propagation behavior in AISI 304 stainless steel. For the $6 \mathrm{~mm}$ diameter rod specimen, growth rates are higher than the standard if correlated in terms of $\Delta K$ but fall in line with the standard if crack closure is taken into account.

\section{Acknowledgements}

The authors are grateful to the National Science Council, ROC for financial support for this work through the projects NSC 92-2212-E-002-008 and NSC 93-2212-E002-062.

\section{References}

[1] Corwin WR, Haggag FM, Server WL, editors. Small specimen test techniques applied to nuclear reactor vessel thermal annealing and plant life extension. ASTM Special Technical Publication 1204. Philadelphia: American Society for Testing and Materials; 1993.

[2] Corwin WR, Rosinski ST, van Walle E, editors. Small Specimen Test Technique ASTM Special Technical Publication 1329. Philadelphia: American Society for Testing and Materials; 1998.

[3] Sokolov MA, Landes JD, Lucas GE, editors. Small specimen test techniques: Fourth volume. ASTM Special Technical Publication 1418. Philadelphia: American Society for Testing and Materials; 2002.

[4] James LA, Straalsund JL, Bauer RE. Optimization of fatigue-crack growth testing for first wall materials development evaluations. J Nucl Mater 1979(85-86):851-4.

[5] Rao GR, Chin BA. Comparison of small-scale bending and axial fatigue specimens. ASTM Special Technical Publication no. 1125, 1992. p. 1095-1102.

[6] Lucon E, Bicego V, D’Angelo D, Fossati C. Evaluating a serviceexposed component's mechanical properties by means of subsized and miniature specimens. ASTM Special Technical Publication 1204, 1993. p. $311-23$.

[7] Marmy P, Victoria M. Tensile and fatigue properties of DIN 1.4914 martensitic stainless steel after $590 \mathrm{MeV}$ proton irradiation. J Nucl Mater 1992(191-194):862-7.

[8] Jeelania S, Natarajan R, Reddy GR. A subsized fatigue specimen. Int J Fatigue 1986(8):159-64.

[9] Rickerby DG, Fenici P. Simultaneous light ion irradiation and fatigue experiment for the Ispra cyclotron. J Nucl Mater 1981(103/104): 1577-82.

[10] Rao GR, Chin BA. Development of a miniature-disk bending fatigue specimen. ASTM Special Technical Publication 1204, 1993. p. $267-$ 74.

[11] Nunomura S, Noguchi S, Okamura Y, Kumai S, Jitsukawa S. Two micro fatigue test method for irradiated materials. ASTM STP 1204, 1993. p. 275-88.

[12] Sriharsha HK, Pandey RK, Chatterjee S. Towards standardising a sub-size specimen for fatigue crack propagation behaviour of a nuclear pressure vessel steel. Eng Fract Mech 1999(64): $607-24$.

[13] Shin CS, Chen PC. Fatigue crack propagation testing using subsized rotating bending specimens. Nucl Eng Design 2004(231):13-26.

[14] Shin CS, Cai CQ. Experimental and finite element analyses on stress intensity factors of elliptical surface crack in a circular shaft under tension and bending. Int J Fract 2004(129):239-64.

[15] Shin CS, Cai CQ. A normalized area-compliance method for monitoring the surface crack development in a cylindrical rod. Int $\mathrm{J}$ Fatigue 2005(27-7):801-9.

[16] Kikukawa M, Jono M, Tanaka K. Fatigue crack closure behaviour at low stress intensity level. In: Proceedings of the ICM2, Boston 1976. p. 254-77.

[17] Fleck NA. Influence of stress state on crack growth retardation. Basic Questions in Fatigue ASTM STP 924, 1988. p. 157-83.

[18] Varvani-Farahani A, Topper TH. Short fatigue crack characterization and detection using confocal scanning laser microscopy (CSLM). Nontraditional Method of Sensing Stress, Strain, and Damage in Materials and Structures ASTM STP 1318. p. 43-55. 
[19] Saka M, Sato I, Abe H. NDE of 3-D surface crack using magnetic field induced by DC current flow. NDT \& E Int 1997;31: 325-8.

[20] Okada Hiroshi, Zhao Wei, Atluri Satya N, Sampth SG. A computational approach to determining the depth of surface flows by the ACPD technique. Eng Fract Mech 1992;43:911-21.

[21] Saka M, Oouchi A, Abe H. NDE of a crack by using closely coupled probes for DCPD technique. ASME J Press Vessel Technol 1998;118:198-202.

[22] Romilly DP. Development of the DC potential drop method for oneand two-directional crack growth monitoring. Exp Techniques 1990;14:22-8.

[23] Beevers CJ. Advances in crack length measurement. London (UK): EMAS; 1982.

[24] Ragazzo C, Hertzberg RW, Jaccard R. A method for generating fatigue marker bands using a constant $K_{\max }$ test procedure. J Test Evaluat 1995(23):19-26.
[25] Caspers M, Mattheck C, Munz D. Propagation of surface cracks in notched and unnotched rods. A method for generating fatigue marker bands using a constant $K_{\max }$ test procedure, 1990. p. 365-89.

[26] Fleck NA, Smith IFC, Smith RA. Closure behaviour of surface cracks. Fatigue Fract Eng Mater Struct 1983;3:225-39.

[27] Dawicke DS, Grandt Jr AF, Newman Jr JC. Three-dimensional crack closure behavior. Eng Fract Mech 1990;36:111-21.

[28] Troha WA, Nicholas T. Grandt Jr, AF. Three dimensional aspects of fatigue crack closure in surface flaws in polymethylmethacrylate material. ASTM STP 982, 1988. p. 598-616.

[29] Ray SK, Perez R, Grandt Jr AF. Fatigue crack closure of corner cracks located at holes loaded in tension or bending. Fatigue Fract Eng Mater Struct 1987(10):239-50.

[30] ASTM E-647-93, Standard test method for constant load amplitude fatigue crack growth rates above $10^{-8} \mathrm{~m} /$ cycle. Philadelphia, USA: American Society for Testing and Materials; 1993. 